\title{
Política educacional e o direito à educação: estudo da efetivação na rede pública municipal ${ }^{12}$
}

\author{
Educational policy and the right to education: study of effectiveness in the municipal public network \\ La politique éducative et le droit à l'éducation: une étude de l'efficacité du système public municipal
}

\author{
Delyana Santana de Britto Marinho ${ }^{3}$ \\ Universidade do Estado da Bahia \\ Gabriela Sousa Rêgo Pimentel ${ }^{4}$ \\ Universidade do Estado da Bahia
}

\begin{abstract}
Resumo: Este artigo tem como objetivo discutir a efetivação do direito à educação no acesso, permanência e aprendizagem do ensino fundamental das escolas públicas do município de Barreiras-BA. Trata-se de pesquisa qualitativa, por meio de análise documental da legislação educacional, aplicação de questionário aos gestores e análise dos indicadores educacionais. Os resultados viabilizam a instrumentalização do direito à educação, ações para concretização e lacunas a suprir, bem como, políticas de viabilização de vagas para acesso, permanência e controle de evasão escolar. Os indicadores apontaram aprendizagem inadequada, com baixa melhoria no aprendizado do $5^{\circ}$ ano e, também, inadequada do $9^{\circ}$ ano. Reflete uma fragilidade do aprendizado, e aponta como necessário o enfretamento da vulnerabilidade educacional no sistema municipal de Barreiras-BA.
\end{abstract}

Palavras-chave: Direito público subjetivo. Educação básica. Gestão educacional.

\begin{abstract}
This article aims to discuss the realization of the right to education in access, permanence and learning of elementary education in public schools in the city of BarreirasBA. It is a qualitative research, through documentary analysis of educational legislation, application of a questionnaire to managers and analysis of educational indicators. The results make possible the instrumentalization of the right to education, actions to materialize and gaps to be filled, as well as policies to enable vacancies for access, permanence and control of school dropout. The indicators pointed to inadequate learning, with little improvement in the 5th grade and inadequate 9th grade learning. It reflects a fragility of learning, becoming necessary to face the educational vulnerability in the municipal system of Barreiras-BA.
\end{abstract}

Keywords: Right to education. Basic education. Educational management.

\footnotetext{
${ }^{1}$ Este texto é resultado da Dissertação de Mestrado de: MARINHO, Delyana Santana De Britto. O direito à educação e a garantia do acesso, à permanência e à aprendizagem no Ensino Fundamental. 2020. Dissertação (Mestrado) - Programa de Pós-Graduação em Educação e Contemporaneidade, Universidade do Estado da Bahia, Salvador, 2020. Parecer Consubstanciado do Comitê de Ética em Pesquisa: CAAE 33812720.6.0000.0057.

${ }^{2}$ Este texto faz parte das atividades do Grupo de Pesquisa: EDUCATIO - Políticas Públicas e Gestão da Educação, da Universidade do Estado da Bahia (UNEB).

${ }^{3}$ Mestre em Educação e Contemporaneidade, pela Universidade do Estado da Bahia. Professora Universitária. Barreiras, Bahia.E-mail: delyanabritto@gmail.com. Lattes: http://lattes.cnpq.br/7791153573765181. ORCID: https://orcid.org/0000-0002-4677-6205.

${ }^{4}$ Doutora em Educação, pela Universidade Católica de Brasília. Professora Titular da Universidade do Estado da Bahia, atuando no Programa de Pós-Graduação em Educação e Contemporaneidade (PPGEduc). Salvador, Bahia. E-mail: meg.pimentel@uol.com.br. Lattes: http://lattes.cnpq.br/7308959142072698. ORCID: https://orcid.org/0000-0002-4278-0573.
} 
Résumé: Cet article vise à discuter de l'efficacité du droit à l'éducation dans l'accès, la permanence et l'apprentissage de l'éducation de base dans les écoles publiques de la ville de Barreiras-BA. Il s'agit d'une étude, avec une analyse documentaire de la législation éducative, l'application d'un questionnaire aux gestionnaires et l'analyse des indicateurs éducatifs. Les résultats permettront d'instrumentaliser le droit à l'éducation, de concrétiser des actions et de combler des lacunes, ainsi que des politiques d'accès à des places gratuites, de durabilité et de lutte contre l'abandon scolaire. Les indicateurs indiquent un apprentissage inadéquat, avec une faible amélioration de l'apprentissage en cinquième année et un apprentissage inadéquat en neuvième année. Cela reflète également une fragilité de l'apprentissage. Il faut donc s'attaquer à la fragilité de l'éducation dans le système municipal de Barreiras-BA.

Mots-clés: Droit à l'éducation. L'éducation de base. Gestion pédagogique.

Recebido em: 13 de julho de 2021

Aceito em: 05 de setembro de 2021

\section{Introdução}

O Direito Educacional fundamenta-se pela interação de normas dispositivas, prescritivas e imperativas e revela a imposição de limites, deveres e obrigações para a atuação do poder público em matéria de educação. Assim, a temática abordada possui relevância social e jurídica, por ser a educação um direito público subjetivo do indivíduo, cujo objetivo é o pleno desenvolvimento da pessoa, o preparo para o exercício da cidadania e a qualificação para o trabalho.

Em vista disso, a efetivação plena da educação, pautada na gestão democrática e consolidação dos preceitos normativos educacionais, cumprirá o papel constitucional a que foi designada, e compele o Estado a adotar políticas ativas para o acesso ao ensino, a permanência na educação escolar, como, também, a consumação da aprendizagem.

Nesta concepção, normas jurídicas específicas à educação são instituídas, reformas educacionais estabelecidas, aspirando à realização desse direito público. Todavia, é possível verificar o descumprimento desses preceitos normativos em unidades federativas, de modo a não satisfazer concretamente o direito à educação.

Os resultados obtidos com a pesquisa viabilizam a instrumentalização do direito à educação no município de Barreiras-BA, com indicação de lacunas a serem supridas e orientação acerca de como concretizá-las. Em vista disso, identifica-se a relevância jurídica, social e acadêmica da pesquisa desenvolvida, cujo intuito primordial foi a concretização do direito fundamental à educação neste município.

A abordagem qualitativa decorreu da realização de pesquisa bibliográfica e documental, a partir da investigação sobre um dado fenômeno. Os dados foram coletados com base na análise documental da legislação específica da educação, com acesso às leis atualizadas; nos questionários 
e entrevistas aplicados aos participantes da pesquisa, os gestores escolares do município de Barreiras-BA, efetivados por meio do envio do formulário Google Forms ao e-mail dos gestores; nos dados contidos nos exames de diagnóstico dos indicadores educacionais, com análise dos resultados da Prova Brasil, Censo Escolar, e consequente índice do IDEB no município; e pela análise subjetiva, por parte do pesquisador, registro e interpretação das informações coletadas a partir da análise bibliográfica, o que configura o caráter descritivo da pesquisa.

A fim de caracterizar as estratégias de gestão que garantam a permanência e a aprendizagem dos alunos do ensino fundamental da escola pública do município de BarreirasBA, foram analisados os indicadores educacionais Prova Brasil, Censo Escolar, e índices do IDEB dos anos de 2017 e 2019, além da aplicação de questionário aos gestores escolares do munícipio. Para a identificação da percepção dos gestores escolares em relação à efetivação do direito à educação quanto ao acesso e à permanência, foi aplicado questionário.

Assim, este trabalho tem como finalidade apresentar os resultados da pesquisa desenvolvida com o objetivo de discutir a efetivação do direito à educação no acesso, permanência e aprendizagem do ensino fundamental das escolas públicas do município de Barreiras-BA.

\section{Plano Municipal de Educação (PME) - Barreiras-BA}

A Constituição Federal, em abordagem acerca dos sistemas de ensino, estabelece a organização em regime de colaboração entre os entes políticos, e define, em seu artigo 211 , $\S 2^{\circ}$, que cabe aos municípios atuação prioritária na educação infantil e no ensino fundamental. Essa indicação autoriza que os municípios editem normas de cunho pedagógico para atendimento às suas condições e necessidades (BRASIL, 1988).

Em vista disso, o exercício da autonomia para o planejamento pedagógico dos municípios encontra limitações decorrentes da obrigatoriedade de cumprir as determinações lançadas pela legislação educacional, que, por sua vez, devem obediência aos parâmetros constitucionalmente definidos para a satisfação do direito à educação. Com base no permissivo constitucional, os entes políticos - no caso em análise, o município - em seu sistema de ensino, podem editar planos municipais de educação, de modo a melhor satisfazer sua realidade social e cultural.

De acordo com Furtado (2019, p. 168), ao optar pela criação do sistema próprio “de ensino, é importante não perder de vista as responsabilidades a serem assumidas pelo poder local, dentre as quais se destacam a organização, o planejamento e a delimitação de suas competências político-pedagógicas, administrativas e financeiras”.

E, pela disposição estabelecida pela Lei Maior, deve garantir a qualidade, a equidade e a universalização do ensino fundamental, parte integrante do ensino obrigatório, com proeminência ao atendimento do padrão mínimo de qualidade. Desse modo, o município de 
Barreiras, localizado na região oeste do Estado da Bahia, através da Lei nº 1.267/2017, promulgou o Plano Municipal de Educação visando traçar diretrizes, metas e estratégias para o desenvolvimento da educação, tendo em vista melhorias nos setores administrativos, estruturais e pedagógicos (BARREIRAS, 2017).

A estruturação do plano municipal de educação é condizente com a disciplina indicada pela LDBEN, de modo que o ensino fundamental tem nove anos de duração, com início aos 6 (seis) anos de idade até os 14 (catorze) anos de idade, considerando a duração regular para os alunos. E, ainda em atendimento aos preceitos legais, o primordial objetivo desta etapa da educação básica é promover a formação básica do cidadão.

Tratando a respeito do contexto educacional brasileiro frente aos objetivos estabelecidos pela Agenda 2030 da ONU, Pimentel (2019, p. 26) explica que "um currículo escolar baseado em competências, conforme prescrito nos documentos deve relacionar os conhecimentos formais e a utilização em situações concretas". Com isso, os currículos precisam ser revistos e adequados às reais necessidades educacionais e à heterogeneidade dos estudantes.

Por essa perspectiva, o Plano Municipal de Educação do Município de Barreiras-BA estabeleceu diretrizes, metas e estratégias tendentes a promover o direito à educação aos seus cidadãos. Existe uma preocupação no sistema municipal em atender aos impositivos da legislação nacional, notadamente quanto à garantia do acesso, permanência e aprendizagem no ensino fundamental da escola pública, enfaticamente pela abordagem da erradicação ao analfabetismo, oferta de educação de qualidade e gestão democrática.

Aliado ao acesso e à permanência, enfatiza, oportunamente, o desafio municipal da oferta de uma educação de qualidade, com as melhorias necessárias e que forem apontadas de acordo com os índices medidores da qualidade da educação. Como dito antes, a definição de educação de qualidade apresenta-se como um desafio às instituições públicas e privadas, bem como ao legislativo, em razão da insuficiente orientação das diretrizes delineando a oferta de qualidade na educação.

Então, na pretensão de esclarecer a educação de qualidade, instrumentos normativos são estabelecidos e o cumprimento das metas e estratégias para uma educação de qualidade já se mostram como passo inicial para a melhoria do processo de ensino-aprendizagem. Para a sua concretização, a organização do ensino, em âmbito federativo, deve sopesar as carências locais, regionais e culturais na definição de metas e satisfação das necessidades peculiares do município.

A par disso, relembre-se a atuação democrática no contexto escolar, em que, valendose da mútua participação de toda a comunidade escolar (formada pelos professores, alunos, gestores, coordenadores, funcionários, dentre outros), todos direcionados à identificação das circunstâncias que requerem melhoria, capacitação, estrutura física e política, propiciará a 
materialização do direito à educação, nesta hipótese, na seara municipal. Grife-se, por oportuno, a aplicação de recursos públicos na seara educacional, com a intenção de satisfazer as necessidades locais, quanto à expansão como melhoria do padrão de qualidade e equidade.

\section{Os dados em discussão}

O município de Barreiras-BA, lócus da pesquisa, possui, em sua rede municipal de ensino, 66 (sessenta e seis) escolas ofertando o ensino fundamental, anos iniciais e finais. As escolas municipais contam, atualmente, com 1.056 (mil e cinquenta e seis) professores atuantes e 39 (trinta e nove) gestores escolares, conforme dados do Censo Escolar do ano de 2018 e informações da Secretaria Municipal de Educação. Os questionários foram enviados para $100 \%$ dos diretores.

Em análise contextualizada das metas definidas no Plano Municipal de Educação, estabeleceu-se um recorte para tratar especificamente da meta 07, demarcada pela abordagem da qualidade da educação fundamental, com melhoria do fluxo escolar e aprendizagem, traçando paralelo com as questões apresentadas aos gestores escolares do município de Barreiras-BA.

A análise da efetividade da abordagem constante da meta 7 em fomentar a qualidade da Educação Infantil e do Ensino Fundamental, pressupõe, previamente, a garantia do acesso à escola para essas crianças. Na intenção de identificar a oferta de vagas para a garantia do acesso e, ainda, a permanência dos alunos matriculados nas escolas municipais no Ensino Fundamental anos iniciais e finais, foram apresentados questionamentos aos gestores escolares, e serão classificadas como Escola A, Escola B, Escola C e Escola D.

Para identificar o número de vagas ofertadas nas escolas para o ensino fundamental, questionou-se ao gestor a quantidade de vagas, para os anos iniciais e anos finais, disponibilizada na escola em que atua. As respostas a esse quesito podem ser verificadas no quadro 1.

Quadro 1 - Quantidade de vagas ofertadas para o ensino fundamental no município

\begin{tabular}{|l|c|c|} 
& $\begin{array}{c}\text { Ensino fundamental número de } \\
\text { vagas anos iniciais }\end{array}$ & $\begin{array}{c}\text { Ensino fundamental } \\
\text { número de vagas anos finais }\end{array}$ \\
\hline ESCOLA A & 610 & NÃO SE APLICA \\
\hline ESCOLA B & NÃO SE APLICA & 1000 \\
\hline ESCOLA C & 430 & NÃO SE APLICA \\
\hline ESCOLA D & 400 & NÃO SE APLICA \\
\hline
\end{tabular}

Fonte: Pesquisa de campo (2020). 
As Escolas A, C e D ofertam apenas a etapa inicial do ensino fundamental, não tendo o seguimento para os anos finais, de modo que os alunos, após concluírem a primeira etapa, são direcionados às escolas municipais que ministrem os anos finais do ensino fundamental. A Escola B disponibiliza para a comunidade os anos finais do ensino fundamental.

Questionados acerca da adequação do número de vagas ofertado pela escola, comparando com a demanda da localidade, $75 \%$ dos gestores entrevistados entendem que o número ofertado atende à necessidade do local em que se insere, e 25\% declaram não ser suficientes tendo em vista a relação contex to da localização da escola e o número de indivíduos da região. Libâneo, Oliveira e Toschi (2012, p. 239) esclarecem que, sendo a "escola uma instituição social, é necessário sempre considerar que as concepções estão vinculadas a necessidades e demandas do contexto econômico, político, social e cultural de uma sociedade e a interesses de grupos sociais”.

Por esta constatação, identifica-se que, no município estudado, a oferta de vagas para ingresso ao ensino fundamental tem sido adequada para a satisfação do direito ao acesso à educação. No entanto, em que pese ser mínimo o percentual de insatisfação do número de vagas, é possível a reanálise pela Secretaria Municipal de Educação para viabilizar o aumento da quantidade de vagas, que podem estar limitadas pela condição do espaço físico da escola.

Ainda sob o viés de acesso ao ensino fundamental, indagou-se aos gestores escolares sobre a existência de alguma restrição para matrícula na escola em que atua. Das escolas pesquisadas, apenas a Escola B apresentou a incidência de restrição para a efetivação da matrícula, e isto em decorrência de distorção série e idade. As demais não indicaram qualquer restrição para a matrícula dos sujeitos.

Após a verificação de existência ou inexistência de restrição para a matrícula, questionou-se o número de alunos efetivamente matriculados no Ensino Fundamental Anos iniciais, verificando-se que, nas Escolas A e D, o número de vagas ofertado não foi preenchido em sua integralidade, o que denota a capacidade de recebimento de novos indivíduos (com possibilidade de matrículas), e o favorecimento da efetivação do direito ao acesso ao ensino fundamental - anos iniciais.

A Escola C encontra-se com seu número de vagas totalmente preenchido, e isso implica o cumprimento, pelos pais e responsáveis, do dever de oportunizar e matricular os sujeitos na escola, enquanto espaço formal da educação. No que tange à matrícula no ensino fundamental - anos finais, a Escola B teve quase que a integralidade de suas vagas preenchidas, e isso pode, também, demonstrar a responsabilidade da família em garantir aos indivíduos o acesso a esta etapa da educação básica no seio da escola. Arelaro, Jacomini e Klein (2011) reafirmam a 
característica de direito público subjetivo do indivíduo, de modo que é preciso que o Estado garanta vagas e infraestrutura adequada para a concretização do direito.

Na seara do ensino fundamental, apontada pela Constituição Federal como etapa prioritária a ser garantida pelo sistema de ensino municipal, incumbe ao município a inserção de políticas públicas destinadas à promoção da infraestrutura local da sua organização estrutural, seja com quantidade e qualificação de professor es, investimento em estrutura física, oferta de merenda escolar adequada, dentre outras questões necessárias para a efetivação do direito à educação.

Como se verifica nas informações dos gestores escolares quanto ao número de vagas oferecido pelo município de Barreiras-BA para o ingresso no ensino fundamental, percebe-se que o direito ao acesso ao ensino fundamental vem sendo efetivado neste município, em nítida obediência aos preceitos normativos municipais e nacionais.

Atrelado a esta constatação, identifica-se uma preocupação dos gestores em promover o acesso às vagas ofertadas bem como a permanência dos alunos matriculados, com a adoção de ações de reinserção e/ou acompanhamento junto à família dos alunos faltosos. Importante destacar o estímulo normativo em garantir o acesso dos alunos à escola, apontada como local social e juridicamente adequado para o processo de ensino-aprendizagem, bem como a permanência dos alunos na série adequada, na tentativa de evitar a distorção da idade/série.

Todavia, em que pese a contextualização e as considerações escaneadas pelo legislador para defender a escola como o espaço formal de ensino, no contex to inusitado em que o mundo foi inserido pela pandemia do Covid-19, o espaço escolar foi transferido para o espaço doméstico, com inevitável articulação família e escola visando ao aproveitamento do ano letivo. Realidade esta que clama a reflexão do direito ao acesso às etapas da educação com a restrição ao espaço escolar, como delineado legalmente.

Narrando a respeito da distorção idade-série, Portella, Bussmann e Oliveira (2017, s.p) definem que a distorção idade-série é a diferença "entre a idade adequada para a série do estudante e a idade real do estudante. O recomendado é que esta diferença seja zero, isto é, que o estudante esteja na série adequada para sua idade”. Pelas respostas apresentadas pelos gestores das escolas pesquisadas, a distorção idade-série não representa óbice à consagração do direito ao acesso e permanência à educação no município estudado.

Todavia, esta distorção pode ser um encalço na garantia da aprendizagem, por representar o retardamento evolutivo do indivíduo no sistema da educação quando comparado com o ingresso na idade escolar indicada. Sobre a quantidade de des istências de matrícula nas escolas municipais analisadas, o índice de permanência é consideravelmente mais alto do que o percentual de desistência, que é de 6,401\%, e 
permanência de 93,59\%, identificando-se inexpressiva evasão escolar neste ano de 2020, mesmo diante dos transtornos provocados pela pandemia do Covid-19.

No aspecto relacionado à evasão escolar, que, segundo o INEP, é o desligamento do aluno da escola sem retorno no ano posterior, as escolas pesquisadas apresentam estratégias gerenciais para evitar a sua ocorrência. Veja-se as respostas apresentadas pelos gestores escolares no que concerne ao percentual de desistência de matrículas, especificadas no quadro 2:

Quadro 2 - Respostas ao questionamento acerca da desistência de matrículas: estratégias adotadas pela escola

Pesquisa sobre o motivo, predominante dois: mudança da família para zona

ESCOLA A rural ou outro bairro ou busca por emprego. Feito isso, informar a órgãos de assistência à criança, caso não estejam matriculadas em outra escola.

A possibilidade de longa duração da suspensão das atividades escolares presenciais por conta da pandemia da COVID-19 poderia acarretar retrocessos do processo educacional e da aprendizagem aos estudantes submetidos a longo período sem atividades educacionais regulares, tendo em vista a indefinição do tempo de isolamento e o aumento da evasão escolar. Vimos que poderiam ser evitadas ou amenizadas com a retomada dos estudos de forma remota, por meio da orientação da equipe gestora e pedagógica

ESCOLA B escolar (coordenação e professores) e com o apoio das famílias.

As medidas iniciais foram:

Comunicação com todos os pais ou responsáveis pelos alunos, a princípio pelo número de celular fornecido no ato da matrícula para informá-los sobre a retomada dos estudos e metodologias a serem utilizadas.

Formação de grupos, por turma, utilizando a mídia social de longo alcance WhatsApp, como meio de acesso para estimular e orientar os estudos.

Ligação telefônica para todos os pais para avaliar o processo de aprendizado.

ESCOLA C Acompanhar o número de alunos faltosos, contato constante com as famílias. Projeto Alô Família;

ESCOLA D Contato permanente com as famílias; Turmas por níveis de aprendizagem.

Fonte: Pesquisa de campo (2020).

Em resposta ao questionamento no tocante à eficácia das medidas adotadas e acima descritas para evitar a evasão, responderam os gestores sobre a eficácia, na forma externada no quadro 3:

Quadro 3 - Respostas ao questionamento acerca da eficácia das medidas adotadas pela escola para evitar a evasão escolar

ESCOLA A sociais pesam muito. Escola fica agindo posterior ao fato. Como prevenção, de modo geral, investir na afetividade, acolhida das famílias, qualidade de ensino.

ESCOLA B Está havendo uma participação efetiva dos alunos. Porém, não temos a garantia de que não haverá evasão.

ESCOLA C $\quad 90 \%$ de eficácia.

ESCOLA D Sim. Temos um percentual $0,1 \%$ de evasão.

Fonte: Pesquisa de campo (2020). 
Diante das estratégias apresentadas, verifica-se a preocupação dos gestores escolares em acompanhar a permanência dos alunos matriculados na escola de modo que se identifica, neste município, nas escolas pesquisadas, a garantia de permanência no Ensino Fundamental, indo ao encontro dos ditames legais direcionados à efetivação do direito à educação em suas múltiplas facetas.

De modo que, não basta aos gestores escolares garantir o acesso dos sujeitos à escola, mas, também compete à gestão democrática estabelecer estratégias eficientes e eficazes para garantir que os indivíduos matriculados permaneçam inseridos no contexto escolar e, assim, possibilitar a consolidação do direito à educação. Lenskij (2006, p. 56) assegura que a permanência na escola é direito público subjetivo e poderá ser alvo de “ação judicial por parte dos responsáveis por criança e adolescentes em fase de escolaridade obrigatória, na falta de cumprimento por parte do Poder Público. Significa o uso dos direitos de cidadania, ou direitos fundamentais por parte de seu titular".

É nessa perspectiva que a Constituição Federal traça, também, a interrelação família e escola para a promoção da continuidade no vínculo escolar, quando esboça em seu artigo 208, $\$ 3^{\circ}$ que "compete ao Poder Público recensear os educandos no ensino fundamental, fazer-lhes a chamada e zelar, junto aos pais ou responsáveis, pela frequência à escola” (BRASIL, 1988).

$\mathrm{Na}$ tentativa de identificar o índice de aprendizagem dos alunos matriculados e permanentes na escola municipal do ensino fundamental quanto ao resultado da Prova Brasil, indagou-se aos gestores acerca do índice de aprendizagem na escola. Assim, 50\% dos gestores consideraram que o índice de aprendizagem foi satisfatório e outros 50\% consideraram o resultado razoável.

Como é sabido, o mundo vivencia severas restrições em virtude da pandemia do Covid19. E a escola também vem sofrendo significativos impactos decorrentes da imposição do isolamento social, que implicou no fechamento provisório das instituições de ensino naquilo que se refere à presença física dos sujeitos nelas envolvidos.

Assim, adaptações mostraram-se primordiais para o atendimento das necessidades impostas em diversos setores, inclusive para a escola. Diante do contexto mundial e para aproveitamento do ano letivo, indagou-se aos gestores escolares quais estratégias de aprendizagem foram utilizadas durante a suspensão das aulas presenciais pelo contingenciamento social e se foram efetivas para a satisfação do direito à aprendizagem. 
Em resposta ao questionamento acima delimitado, primeiro, relativamente às estratégias de aprendizagem utilizadas pela escola, responderam os gestores as estratégias, como delineado no quadro 4:

Quadro 4 - Respostas ao questionamento sobre as estratégias de aprendizagem que foram utilizadas durante a suspensão das aulas presenciais em virtude da pandemia do coronavírus

ESCOLA A Vídeo aulas (celulares de professores e alunos) e entrega de atividades remotas. Envio dos roteiros de aula pelo grupo de WhatsApp da turma, com o passo a passo para que o aluno desenvolva o estudo em seu domicílio.

Entrega dos roteiros de aula em material físico para retirada na secretaria da escola pelas famílias de alunos que não dispõem de celular e internet.

Utilização de metodologias variadas de orientação para o estudo remoto: indicação de leituras, de atividades, de slides explicativos, de vídeo, aulas disponíveis na internet em canais educativos; de vídeo aulas produzidas pelo próprio professor; orientação de leitura de paradidáticos e disponibilização no formato digital; aula virtual.

Interação e retirada de dúvidas dos alunos através de contato pelo celular do professor, via chat no grupo de WhatsApp da turma ou por meio de aula virtual.

ESCOLA B pelos professores de AEE.

Utilização de instrumentos avaliativos diversos:

realização de atividades que contemplam os principais objetos de conhecimento abordados nos roteiros de estudos das atividades remotas; criação de materiais vinculados aos conteúdos estudados: produção de textos, vídeos, roteiros, relatos, experiências, história em quadrinhos, mapas mentais, cartazes; realização de atividade avaliativa com questões discursivas ou de múltipla escolha, no formato Google Forms; correção das atividades por meio de roteiro de correção a ser disponibilizado pelo professor, vídeos com correção do professor para o aluno e vice-versa; realização de avaliação oral individual e correção de atividades acerca de temas estudados previamente, via aula virtual ou via WhatsApp; realização de simulado interdisciplinar via formulário Google Forms.

ESCOLA C Trabalhamos com atividades remotas.

Mobilização e conscientização da comunidade sobre a atual situação;

Criamos uma central telefônica para atender às dúvidas e queixas das famílias;

ESCOLA D Criamos grupo para estudo e orientação via WhatsApp;

Aulas não presenciais em vídeos, 7 lives;

Disponibilizamos conteúdos em todas as redes sociais da escola;

Entrega de módulos de atividades de todas as disciplinas para realização em domicílio;

Fonte: Pesquisa de campo (2020).

Alusivo à pergunta concernente à eficácia das estratégias relatadas, os gestores responderam sobre este ponto, como retratado no quadro 5: 
Quadro 5 - Respostas ao questionamento sobre considerarem efetivas as estratégias adotadas para a satisfação do direito à aprendizagem

\begin{tabular}{|l|l|}
\hline ESCOLA A & $\begin{array}{l}\text { Não. Seria necessário muito investimento em Tecnologia de Informação e } \\
\text { Comunicação, como internet banda larga na escola e acesso gratuito nos } \\
\text { lares dos alunos. }\end{array}$ \\
\hline ESCOLA B & $\begin{array}{l}\text { Sim. Todos os roteiros de estudos estão pautados nas habilidades e } \\
\text { competências previstas para cada etapa de ensino, alinhadas à BNCC e à } \\
\text { Proposta Curricular Municipal, e com metodologias variadas para garantir } \\
\text { o aprendizado. Porém, não podemos descartar os casos de alunos que não } \\
\text { realizam as leituras e atividades por motivos variados, mesmo com todo o } \\
\text { empenho da escola junto às famílias. }\end{array}$ \\
\hline ESCOLA C & $\begin{array}{l}\text { Não substituem as aulas presenciais, mas, diante dos recursos que a escola } \\
\text { e as famílias dispõem, é o que pode ser feito atualmente. }\end{array}$ \\
\hline ESCOLA D & Sim. Muito.
\end{tabular}

Fonte: Pesquisa de campo (2020).

Observa-se que as ações adotadas pelos gestores escolares visaram à continuidade do atendimento da demanda escolar na tentativa de ofertar o ensino aos alunos matriculados. À medida que as novas demandas incidiram, providenciaram uma mínima ressignificação, valendo-se de instrumentos já disponíveis. É visível a intenção em cumprir as metas definidas no PME, relativamente quanto à elaboração de planos de ação para o enfrentamento da situação de pandemia e promover a educação com o desenvolvimento de recursos pedagógicos.

Todavia, mesmo que tenham as escolas municipais se reinventado para evitar prejuízos pedagógicos, é notório o desabastecimento da rede pública de ensino na oferta do ensino a distância por questões inúmeras como: a condição socioeconômica dos alunos matriculados, que, em sua maioria considerável, não possui acesso à rede de internet; a ausência, neste período, da merenda escolar - muitas vezes a única refeição do dia das crianças; o despreparo dos pais e responsáveis para o acompanhamento desses indivíduos - já que se impõe o ensino remoto como única via de manutenção da oferta do ensino -, dentre outras questões impeditivas da efetivação da aprendizagem.

Explicam Souza, Couto e Couto Diniz (2020) que a emergência deflagrada pela situação de pandemia acarretou maior vulnerabilidade dos alunos ao denominado fracasso escolar, visivelmente em razão da condição precária para continuidade da aprendizagem pela dificuldade com o acesso à internet, apropriação dos conteúdos, condições de estudo domiciliar.

A partir dos relatos presentes no questionário, serão avaliados os resultados da Prova Brasil aplicada aos alunos do ensino fundamental da rede pública municipal de ensino nos anos de 2017 e 2019, cujos resultados sinalizaram os gestores serem satisfatórios ou razoáveis, e, assim, analisar a efetivação do direito à educação em Barreiras-BA. 
A Avaliação Nacional do Rendimento Escolar (ANRESC) - Prova Brasil desenvolvida pelo Instituto Nacional de Estudos e Pesquisas Educacionais Anísio Teixeira (Inep/MEC) é uma avaliação bianual aplicada aos alunos do $5^{\circ}$ ano e $9^{\circ}$ ano do ensino fundamental, nas escolas com, no mínimo, 20 alunos matriculados nas etapas avaliadas, para fins de diagnóstico da qualidade do ensino ofertado.

No município investigado, o resultado da Prova Brasil, no ano de 2017, discriminando o índice de aprendizado na etapa escolar, foi considerado satisfatório $50 \%$ e razoável $50 \%$ para os gestores escolares, como antes exposto. O resultado obtido no ano de 2017, nas escolas da rede municipal, está retratado no quadro 6:

Quadro 6 - Resultado da Prova Brasil no ano de 2017

\begin{tabular}{|c|c|c|}
\hline DISCIPLINA & $5^{\circ}$ ANO & $9^{\circ}$ ANO \\
\hline $\begin{array}{c}\text { LÍNGUA } \\
\text { PORTUGUESA }\end{array}$ & $\begin{array}{l}50 \% \\
1.788 \text { alunos realizaram o teste, e } \\
\text { 884 demonstraram o aprendizado } \\
\text { adequado. }\end{array}$ & $\begin{array}{l}\qquad 9 \% \\
1.494 \text { alunos realizaram o } \\
\text { teste e } 434 \text { demonstraram o } \\
\text { aprendizado adequado. }\end{array}$ \\
\hline MATEMÁTICA & $\begin{array}{l}32 \% \\
1.788 \text { alunos realizaram o teste, e } \\
567 \text { demonstraram o aprendizado } \\
\text { adequado. }\end{array}$ & $\begin{array}{c}11 \% \\
1.494 \text { alunos realizaram o } \\
\text { teste e } 171 \text { demonstraram o } \\
\text { aprendizado adequado. }\end{array}$ \\
\hline
\end{tabular}

Fonte: Brasil, 2018.

O processo de avaliação externa dinamizado pela Prova Brasil, ainda que tenha por objetivo identificar a qualidade do ensino ofertado, direciona a um resultado mais quantitativo do que qualitativo propriamente. Com a viabilidade de especificar o resultado de cada escola integrante da rede de ensino municipal, alarga a possibilidade de intervenção específica e eficaz no contexto escolar necessitado.

A contribuição que se busca com a realização desta avaliação é a identificação de aspectos pertinentes ao processo de ensino e aprendizagem em que é possível se estabelecer melhora na escrita, leitura e condições de resolver problemas ainda no ensino fundamental. Aliada ao teste direcionado às disciplinas indicadas, a resposta do questionário socioeconômico retrata a influência do meio externo ao ambiente escolar no próprio processo educacional, e pode contribuir para o melhoramento do fim social da educação.

Em abordagem sobre a qualidade do ensino, Klein (2006) relata que o ambiente familiar é um aspecto importante a ser considerado, seja pela disponibilização de materiais adequados seja pelo estímulo doméstico à frequência na escola e ao aprendizado, já que a qualidade do ensino deve perpassar pelo acesso à educação, ao aprendizado e a evolução nas etapas subsequentes. 
Verificou-se que o resultado da proficiência em língua portuguesa dos alunos do $5^{\circ}$ ano do ensino fundamental foi taxado em $50 \%$ de aprendizagem, de modo que a metade dos alunos submetidos à Prova Brasil demonstraram aprendizado adequado. Contudo, os outros 50\% não obtiveram um aprendizado que possa ser contabilizado. O que demonstra que, neste quesito, o direito à aprendizagem pode ser caracterizado como não efetivo para parte considerável dos alunos matriculados e que frequentam a escola.

Para estes mesmos alunos, quanto aos quesitos de matemática, o percentual de aprendizagem adequado foi de apenas 32\% no contexto dos alunos participantes, cujo percentual representa que menos da metade dos alunos não possui o domínio de cálculo esperado para a etapa escolar. Esses dados provocam genuína preocupação e devem impulsionar a adoção de políticas municipais ativas destinadas a reverter esse déficit de aprendizagem no município.

Quanto aos alunos matriculados no $9^{\circ}$ ano, os índices representativos do aprendizado adequado são ainda menores. Como se verifica, em língua portuguesa obteve-se o percentual de aprendizado adequado em apenas $29 \%$ e em matemática o percentual de $11 \%$, situação esta que merece atenção tantos dos gestores escolares quanto da Secretaria Municipal de Educação (BRASIL, 2018).

Impõe esclarecer que, de acordo com os descritivos desta área do conhecimento (matemática), o alcance do objetivo de aprendizagem possibilita o desenvolvimento de capacidades como observação, estabelecimento de relações, comunicação de diferentes linguagens, argumentação e validação de processos, além de estimular formas de raciocínio como intuição, indução, dedução e estimativa (BRASIL, 2018).

A realidade fática constatada pelo resultado da Prova Brasil, no ano de 2017, impõe políticas educacionais efetivas tendentes a estabelecer parâmetros para o ensino de qualidade, análise da condição do alunado e identificação, dentro do contexto particularizado de cada escola, das questões que merecem ser superadas para a concretização do ensino de qualidade.

Merece destaque a sinalização antes apresentada de que o fator de aprendizagem não deve ser analisado isoladamente, e sim, levando-se em conta os critérios de influência externa que contribuem, significativamente, para o resultado do processo de ensino e aprendizagem. A descrição presente na meta 7.4 do PME realça a necessária mobilização social e da família em assumir a educação como uma responsabilidade solidária, demonstrando a influência dos elementos extrínsecos à comunidade escolar sobre o rendimento dos alunos (BARREIRAS, 2017).

A efetivação do direito à educação percorre não apenas o acesso à escola - cuja universalização já é viabilizada pela legislação pátria e políticas públicas inclusivas - mas 
impõe, em sua trajetória, a permanência do aluno e sua continuidade nas etapas escolares posteriores, além do seu aprendizado.

Os índices da Prova Brasil demonstram o baixo desempenho dos alunos do ensino fundamental do município investigado, o que pode implicar a reprovação desses alunos e consequente não progressão nas etapas posteriores. Contexto que impõe atenção, pois a não aprovação por baixo desempenho reflete na verificação de problemas estruturais e pedagógicos da escola, além da influência dos fatores externos, culturais e sociais, como já exposto, e, inevitavelmente, retrata a não efetivação do direito à permanência e à aprendizagem.

De acordo com Fernandes (2007, p. 7), o problema ainda reside nas altas taxas de "repetência, na elevada proporção de adolescentes que abandonam a escola sem concluir a educação básica e na baixa proficiência obtida por nossos estudantes em exames padronizados". Com os resultados obtidos na Prova Brasil, utilizados como parâmetro de qualidade do ensino, insta analisar os dados do IDEB no município nos anos de 2017 e 2019 visando constatar a efetivação integral do direito à educação, tanto no acesso, quanto na permanência e no aprendizado dos estudantes.

O Instituto Nacional de Estudos e Pesquisas Educacionais Anísio Teixeira (INEP), no ano de 2007, instituiu o Índice de Desenvolvimento da Educação Básica (IDEB), uma avaliação externa com a finalidade de mensurar a qualidade do ensino ofertado pelas redes de ensino, e, a partir dele, valer-se de políticas educacionais voltadas para a melhoria da qualidade do processo educacional.

Em que pese sua aplicação como indicador eficaz da qualidade da educação, cumpre reforçar que a responsabilidade pelo êxito do ensino não se sustenta apenas com a escola e os sujeitos nela inseridos. Depende, por certo, da adoção de políticas educacionais tendentes a permitir qualificação, estruturação, consciência social, dentre outras questões, e, ainda, a reflexão acerca da prática docente, nível socioeconômico familiar, nível cultural, como bem enfatizam Chirinéa e Brandão (2015).

De acordo com as informações colhidas no INEP (2018), a meta projetada para o $5^{\circ}$ ano do ensino fundamental do município de Barreiras-BA no ano de 2017 foi o índice de 4.6. O índice alcançado pelo município de Barreiras-BA foi escalonado em 5.0, o que representa uma superação da projeção estabelecida e um possível alcance de melhoria no aprendizado dos alunos versus o fluxo de aprovação.

Todavia, para fins de alcançar a meta para 2021 e obter o índice de 6.0, políticas ativas educacionais devem ser implementadas para que o direito à educação, na perspectiva da aprendizagem, seja efetivado. No ano de 2019, o $5^{\circ}$ ano também observou índice superior ao projetado. A projeção do índice para o ano de 2019 foi de 4.9, e o município alcançou o índice 
de 5.1. Para o $9^{\circ}$ ano, a meta projetada foi o índice de 4.4. No entanto, o índice obtido correspondeu a 4.1, escalonado abaixo do esperado, não atingindo a meta em projeção. Por este índice, conclui-se o não alcance do aprendizado e fluxo de aprovação minimante estabelecido, o que implica um baixo nível de aprendizado desses alunos. A mesma situação se repetiu no índice no ano de 2019.

É possível verificar que a projeção do IDEB para o ano de 2019 , no $9^{\circ}$ ano, foi de 4.7, mas, o resultado alcançado correspondeu a 4.3. Pelos índices obtidos nos anos de 2017 e 2019, percebe-se que o nível de rendimento das escolas, considerando a Prova Brasil e o Censo Escolar, encontra-se largamente distante de ser considerado satisfatório para concretizar o direito à aprendizagem dos alunos do ensino fundamental da escola pública do município de Barreiras-BA até 2021.

Diante do que, a atuação conjunta do estado da Bahia junto ao município de Barreiras, com direção de ações técnicas estabelecidas após os resultados dos sistemas de avaliação, pode direcionar à melhoria do ensino ofertado, bem como das condições sociais e estruturais que, como elementos externos, também influenciam no processo de ensino e aprendizagem.

\section{Conclusões}

O direito à educação, delineado no ordenamento jurídico pátrio como direito subjetivo intrínseco à condição humana, direciona-se a promover o desenvolvimento pleno do indivíduo, satisfazendo os ideais próprios para a garantia do princípio da dignidade humana. Em que pese as tentativas normativas de estabelecer a efetivação do direito à educação, a sua satisfação, minimamente considerada, continua sendo um desafio governamental em virtude de questões estruturais, de capacitação, de atendimento às necessidades locais das redes de ensino. $\mathrm{O}$ que é perceptível quando se visualiza a rede pública de ensino, é que se esbarra no engessamento político, cultural e socioeconômico, que dificulta a efetivação do direito à educação, notadamente no concernente à educação básica.

Os resultados obtidos apontam que, em análise dos instrumentos descritos no Plano Municipal de Educação, visualizou-se a inserção das estratégias e metas nacionais para aplicação na seara municipal, com descrição das metas tendentes a concretizar o direito social à educação no ensino fundamental. As normas definidas no PME se coadunam com as normas gerais elencadas pela União e vislumbradas nas normas regulamentadoras da educação.

Em vista da situação de pandemia iniciada no ano de 2020, com imposição de ajustes no contexto escolar relacionados à permanência e à aprendizagem, mostrou-se oportuno questionar aos gestores municipais acerca de adaptações ocorridas na escola, bem como sobre as estratégias de aprendizagem utilizadas e sua eficácia. 
Com relação ao problema da pesquisa foram diagnosticados resultados significativos, os quais serão relatados nos parágrafos seguintes. Os dados obtidos pelos índices educacionais refletem que o direito à aprendizagem não tem se efetivado para um número considerável de alunos integrantes do sistema municipal de ensino, e reclama pela adoção de políticas educacionais voltadas para o melhoramento do padrão de qualidade do ensino.

Quanto aos resultados do IDEB, para o $5^{\circ}$ ano do ensino fundamental, verificouse superação da meta previamente estabelecida para o município investigado tanto no ano de 2017 quanto em 2019, com melhoria no aprendizado dos alunos, representando, com o índice alcançado, que o aproveitamento cognitivo dos alunos se encontra no percentual razoável. Já para o $9^{\circ}$ ano do ensino fundamental, o índice obtido foi enquadrado abaixo do projetado, e conclui-se pela não obtenção de aprendizado e fluxo de aprovação no padrão minimante estabelecido, refletindo em baixo nível de aprendizado desses alunos, tanto em 2017 quanto em 2019.

No que se refere à percepção dos gestores escolares em relação à efetivação do direito fundamental à educação no âmbito do município de Barreiras-BA, demonstraram os gestores escolares o entendimento pela concretização do direito à educação no contexto municipal, em que pese a constatação de aprendizado abaixo do adequado nos índices educacionais. Em relação ao aprendizado dos alunos matriculados no ensino fundamental anos iniciais e finais, entenderam os gestores que este direito é efetivado, ainda que considerando o baixo índice nos indicadores educacionais.

Diante disso, prevalece o entendimento pela necessidade de melhorias na política educacional, neste estudo direcionado à seara municipal, para atender às carências internas e externas. As fragilidades externas, consistentes basicamente na falta de compreensão dos alunos e família quanto a este direito fundamental, com possibilidade de ações voltadas para a conscientização das famílias acerca da importância da educação para modificação, inclusive, de sua condição socioeconômica e de incentivo ao alunado na continuidade das etapas escolares.

Desta forma, espera-se que os achados da pesquisa contribuam para a proposição de diretrizes municipais que venham a minimizar os impactos dos indicadores educacionais na rede municipal de Barreiras-Ba, bem como para a área da política educacional no Brasil. Isto porque os dados apresentados se reportam a contribuir para adoção de políticas públicas municipais destinadas ao melhoramento da qualidade do ensino ofertado. Assim, considerando o contexto pandêmico, questiona-se como se imagina que será o novo resultado para um período no qual a aprendizagem está efetivamente em um ambiente virtual? 


\section{Referências}

ARELARO, Lisete Regina Gomes; JACOMINI, Márcia Aparecida; KLEIN, Sylvie Bonifácio. O ensino fundamental de nove anos e o direito à educação. Educação e Pesquisa. São Paulo, v. 37, n.1, 220p. 3551, jan./abr. 2011. Disponível em: https://www.scielo.br/pdf/ep/v37n1/v37n1a03.pdf. Acesso em: 7 jul. 2021. DOI: $\underline{\text { https://doi.org/10.1590/s1517-97022011000100003. }}$.

BARREIRAS. Lei $\mathbf{n}^{\circ}$. 1.267 de, 22 de agosto de 2017. Dispõe sobre o Plano Municipal de Educação - PME do Município de Barreiras - Ba - Decênio 2014 2024, em consonância com a Lei $n^{\circ}$. 13.005/2014, que trata do Plano Nacional de Educação - PNE, e dá outras providências. Barreiras: Câmara Municipal, [2017]. Disponível em: http://encurtador.com.br/kxFUV. Acesso em: 29 jun. 2021.

BRASIL. Constituição da República Federativa do Brasil de 1988. Brasília, DF: Presidência da República [1988]. Disponível em: http://encurtador.com.br/ensuE. Acesso em: 22 jun. 2021.

BRASIL. Ministério da Educação. Instituto Nacional de Estudos e Pesquisas Educacionais Anísio Teixeira (INEP). Sinopse Estatística da Educação Básica 2018. Brasília: Inep, 2019. Disponível em: http://encurtador.com.br/iGMSU. Acesso em: 11 jul. 2021.

CHIRINÉA, Andréia Melanda; BRANDÃO, Carlos da Fonseca. O Ideb como política de regulação do Estado e legitimação da qualidade: em busca de significados. Ensaio: Avaliação e Políticas Públicas em Educação, Rio de Janeiro, v. 23, n. 87, p. 461-484, abr./jun. 2015.

FERNANDES, Reynaldo. Índice de Desenvolvimento da Educação Básica (Ideb). Brasília: Instituto Nacional de Estudos e Pesquisas Educacionais Anísio Teixeira, 2007.

FURTADO, Rosa Maria Silva. Organização do sistema municipal de ensino de Barreiras-BA: Processos, resultados e propostas. In: PIMENTEL, Gabriela Sousa Rêgo; GUEDES, Marilde Queiroz; SILVA, Nilza da (orgs.) Educação básica: políticas, formação e prática pedagógica.1. ed. Curitiba: Appris, 2019.

KLEIN, Ruben. Como está a educação no Brasil? O que fazer? Ensaio: Avaliação e Políticas Públicas em Educação, Rio de Janeiro, v. 14, n.51, p.139-172, abr./jun 2006. DOI: https://doi.org/10.1590/s0104-40362006000200002.

LENSKIJ, Tatiana. Direto à permanência na escola: a lei, as políticas públicas e as práticas escolares. 2006. 174 fls. Orientadora: Prof. Dra . Maria Beatriz Luce. Dissertação (Mestrado) - Universidade Federal do Rio Grande Sul, Porto Alegre, 2006.

LIBÂNEO, José Carlos; OLIVEIRA, João Ferreira de; TOSCHI, Mirza Seabra. Educação Escolar: políticas, estrutura e organização. 10. ed. rev. e amp. São Paulo: Cortez, 2012.

PIMENTEL, Gabriela Sousa Rêgo. O Brasil e os desafios da educação e dos educadores na Agenda 2030 da ONU. Revista Nova Paideia - Revista Interdisciplinar em Educação e Pesquisa, v. 1, n. 3, p. 22 - 33, 3 dez. 2019. DOI: https://doi.org/10.36732/riep.v1i3.36.

PORTELLA, Alysson Lorenzon; BUSSMANN, Tanise Brandão; OLIVEIRA, Ana Maria Hermeto de. A relação de fatores individuais, familiares e escolares com a distorção idade-série no ensino público brasileiro. Nova economia. Belo Horizonte, v. 27, n. 3, p. 477-509. dez. 2017. DOI: http://dx.doi.org/10.1590/0103-6351/3138.

SOUZA, Roger Marchesini de Quadros; COUTO, José Cláudio Diniz; COUTO DINIZ, Luzia Serapicos Martins. Escolas e a pandemia, ações de enfrentamento do afastamento educacional. Cadernos CERU, 31(1). fls. 99-115. 2020. DOI: https://doi.org/10.11606/issn.2595-2536.v31i1p99-115. 